\title{
Explaining the "ebb and flow" of the problem stream: frame conflicts over the future of coal seam gas ("fracking") in Australia
}

\author{
Paul Fawcett ${ }^{1 *}$, Michael J. Jensen ${ }^{1}$, Hedda Ransan-Cooper ${ }^{2}$ and Sonya Duus ${ }^{1}$ \\ ${ }^{1}$ Institute for Governance and Policy Analysis, University of Canberra, Canberra, ACT, Australia and \\ ${ }^{2}$ College of Engineering and Computer Science, The Australian National University, Canberra, ACT, Australia \\ ${ }^{\star}$ Corresponding author. Email: paul.fawcett@canberra.edu.au
}

(Received 29 December 2016; revised 12 March 2018; accepted 14 March 2018;

first published online 16 May 2018)

\begin{abstract}
Why do issues "fade" from the problem stream? This is an important but underresearched question, which this article examines by looking at the dynamic interaction between frames and frame sponsors. We develop a novel methodological approach that combines algorithmic coding (topic modelling) with hand-coding to track changes in the presence of frames and frame sponsors during periods of intense problematisation ("problem windows") both within continuous contexts and diachronically across different contexts. We apply this approach empirically in a corpus of newspaper articles that pertain to the coal seam gas controversy in Australia - a divisive policy issue where frame conflicts are common. We find that elite actors have a particularly decisive impact on the problem stream in terms of both the evolution and duration of debate. Further, problem windows close in response to three different mechanisms: elite frame convergence; public statements (by government and industry); and elections.
\end{abstract}

Keywords coal seam gas; fracking; framing; multiple streams framework; problem stream; topic modelling

\section{Introduction}

Public policy concerns arise on political agendas within the apertures of policy windows (Kingdon 1997). During this period, various citizen groups, organised interests, think tanks, career civil servants and elected officials frame the debate over an issue (Howlett 1998). Consequently, public policy scholars have held a longstanding interest in frames and framing. Different frames define and problematise policy areas in different ways. Policy actors also use frames to strategically promote their preferred policy preferences over others. The range of frames, the opportunities that exist to deploy them and who deploys what frames are all important questions for policy actors as they attempt to influence policy decisions in their preferred direction (Hajer and Wagenaar 2003; Meyer 2004; Baumgartner et al. 2008). 
This article responds to the recent call to address "head-on" questions about how the different streams within the multiple streams framework (MSF) function and evolve. In particular, it develops a methodology for the identification of problem windows by using topic modelling to isolate periods of enduring problem definition. Although others have examined the MSF at the macro level (e.g. Howlett et al. 2015), we "zoom in" on framing and its role within the problem stream. Studies of problem definition and framing have been important areas in policy studies (e.g. Baumgartner and Jones 1993; Stone 1998), yet the problem stream, within the MSF, has often been studied in the shadow of the politics and policy streams (Knaggård 2015). There has also been a natural tendency to focus on why issues get problematised in the first place, rather than on their "ebb and flow" into and out of public debate. We contribute to this emerging research agenda by looking at why issues "fade" from the problem stream.

Although concerns about framing and its impact on policy debates are not new, the literature on framing has been criticised for reifying frames and presenting them in an overly static way (De Bruycker 2016). This is illustrated by the relative lack of studies that have examined dynamic actor-frame relationships (Van Hulst and Yanow 2016). A diachronic analysis is important to understanding how framing takes place in "real time", but it is also more complex than studying frames alone because diachronic research designs raise various methodological challenges (De Bruycker 2016).

This article addresses these challenges by developing an innovative methodological approach that links problem windows and their duration with an analysis of frames and those who sponsor them. We define problem windows as moments in time when a pressing problem emerges, or there is a perception that a pressing problem has emerged, within the problem stream. Problem windows are said to be closed when an identified problem dissipates in coverage. Dissipation may be the result of problem resolution owing to a policy intervention, changes in the underlying conditions that produced the problem, the emergence of new issues that redirect media attention and so forth. By focussing on periods of heightened attention within the broadcast media around the coal seam gas (CSG) debate in Australia, we contribute to an understanding of the structure of problem windows. The findings indicate that problem windows endure so long as controversies persist. We also find that formal political elites play a significant role in this process as their entry into the debate "crowds out" other frame sponsors. Our analysis extends the recent research into the dynamic role of framing in policy controversies by drawing in contextual factors that shape the aperture and closure of problem windows. We find that changes in the contextual factors that serve as proximate reasons for the opening of a problem window can also be decisive in its closure.

We examine these questions empirically using broadcast media reports on the CSG debate in Australia. CSG is a contentious and controversial policy issue in which frame conflicts are common (Jaspal and Nerlich 2014; Metze 2014; Bomberg 2015; Fawcett and Wood 2017). Opponents of CSG cite the industry's high-risk nature and its potential impacts on water, land rights and health, whereas proponents of the industry stress its low-risk nature and potential to generate economic growth and jobs. CSG activities are currently concentrated in two states in Australia [Queensland and New South Wales (NSW)], which both hold significant natural gas reserves. Production has been taking place in Queensland for several decades, and exploration is at an advanced phase in NSW. The recent 
completion of a liquefied natural gas (LNG) facility on Curtis Island has been heralded as a "game changer" by energy companies with estimates that Australia could become one of the world's top three natural gas producers (NSW Parliamentary Library 2013). The Greens are the only political party that has consistently opposed CSG development. The Coalition and federal Labor party have both been cautious supporters, whereas the NSW Labor party has taken both pro- and anti-CSG positions.

Opposition to CSG in Australia has also persisted, and the terms of the debate have changed over time. These factors create favourable conditions for examining the different reasons why problem windows close and a strong theoretical justification for selecting this case. The findings from this case are also more likely to be generalisable given that it shares many key features with policy controversies taking place elsewhere. The CSG controversy in Australia operates across multiple levels of government (local, state and federal). It also involves diverse actors: a highly organised opposition led by environmentalists and support from businesses interests. These factors make the CSG controversy in Australia a suitable case for drawing broader insights into problem windows as they pertain to other controversial policy issues where important stakeholders exist on both sides.

This article proceeds in four sections. First, we locate this analysis in the literature on the MSF and the problem stream. Second, we operationalise our analysis of the problem stream using a research design that combines topic modelling with human coding. Third, we report on our findings on actor-frame dynamics and problem window closure. Finally, we use the preceding analysis to identify and discuss three different mechanisms that help explain why problem windows close.

\section{The problem stream and frame analysis}

The MSF occupies an important place as a key theoretical approach in the study of public policy and the policy-making process (e.g. Howlett et al. 2015; Cairney and Jones 2016; Jones et al. 2016; Rawat and Morris 2016). ${ }^{1}$ In Agendas, Alternatives and Public Policies, Kingdon (1997) argued that policymaking is made up of three separate and independent streams: the problem stream (problems that are perceived by the public as requiring government action), the policy stream (where experts and policy specialists examine problems and propose policy solutions) and the politics stream (which refers to changes in public opinion, executive or legislative turnover and advocacy campaigns). Kingdon argued that policy change occurs when a policy entrepreneur applies an idea from the policy stream to an issue in the problem stream at a time when this coupling is acceptable within the political stream. This coupling could be triggered by external focussing events (e.g. crises, or accidents), the presence or absence of policy entrepreneurs or institutionalised events such as periodic elections or budget deadlines (Birkland 1997, 1998). Thus, time and timing (along with ambiguity) are critical dimensions in the MSF because one's influence over the policy process will always be temporally conditioned (Zahariadis 2003, 2007).

\footnotetext{
${ }^{1}$ For example, four special issues have been published on the MSF over the past year (see Zohlnhöfer et al. 2015; Weible and Schlager 2016; Zahariadis 2016; Béland and Howlett 2016).
} 
Our particular concern here is with the problem stream, which has been identified as an understudied component of the MSF (Knaggård 2015). A concern with the problem stream is also broadly aligned with recent calls for greater engagement between the MSF and ideas (e.g. Béland 2016; Winkel and Leipold 2016), framing (e.g. Boscarino 2016; Sager and Thomann 2017) and agency (e.g. Mukherjee and Howlett 2015). At the general level, the MSF argues that each stream operates independently up until they cross and a policy window opens. The principle of stream independence has been contested (e.g. Robinson and Eller 2010 ,) but Zahariadis $(2007,81)$ has argued that if it is understood as a "conceptual device" then scholars applying the MSF can assume that the streams act "as if" they were independent. To put it more succinctly, although streams are not empirically independent, when conducting research there is analytical value in approaching an issue from within one stream alone.

We can also analytically distinguish the problem stream because it is underpinned by a qualitatively different kind of logic. Although the politics stream may be influenced by constructions produced in the problem stream, it is fundamentally governed by an electoral calculus and involves coordinating the input of support or political opposition for an initiative (Sager and Thomann 2017). This is a different logic from that which is present in the problem stream, which is concerned with who uses what frames, and to what effect, in the public debate surrounding a contested policy problem. Issues in the problem stream are therefore addressed to a public audience and subject to public criteria of persuasion, rather than the technical criteria of the policy stream or the expedience criteria of the political stream.

The problem stream also exhibits some distinct characteristics at the actor level. For example, Knaggård has argued that "problem brokers" operate to "frame conditions as public problems and work to make policy makers accept these frames" $(2015,452)$. She argues that problem brokers perform a role that is distinct to the problem stream because many actors frame problems without making policy suggestions. This is consistent with Mukherjee and Howlett's $(2015,67)$ "differentiated subsystem approach", which analyses how "distinct subsets of actors" in each of the three streams undertake particular tasks, including the "articulation of problems".

The problem stream also exhibits its own particular flow and temporality. The literature on issue attention cycles (e.g. Downs 1972; Nisbet and Huge 2006) has long shown that policy issues get problematised at different rates. In this article, we capture this variation by referring to "problem windows", which we define as moments in time when a pressing problem emerges, or there is a perception that a pressing problem has emerged, within the problem stream. We describe this as a "window" to emphasise the punctuated nature of these moments as distinct from the overall flow of the problem stream. Problem windows appear when an issue in the problem stream becomes a subject of public contestation and debate. Most analysis has focussed on why problem windows open, rather than on why they close. However, understanding how problem streams "flow" requires a focus on both dimensions. As such, there can be both substantive and analytical reasons for distinguishing the problem stream from the policy and politics streams.

Contestation within the problem stream can also occur in multiple domains, although the broadcast media remains a particularly important venue for at least three reasons (Kingdon 1997). First, broadcast media are a central site where actors on multiple sides of controversial issues are represented and policy actors compete 
to gain legitimacy and construct core meanings (Carragee and Roefs 2004; Gamson 2004). Second, broadcast media outlets serve a legitimation role as an independent actor that selects certain issues, frames and actor representations over others (Gamson and Wolfsfeld 1993; Carvalho 2007; Shanahan et al. 2011; Evensen et al. 2014). Third, messages reach wider publics through the mass media (Kriesi 1995; Boykoff and Boykoff 2004). This is a conclusion supported by a US study on hydraulic fracturing, which found that most citizens continued to source their information from the broadcast media (Stedman et al. 2012).

Although MSF scholars have examined the role played by framing in the problem stream (e.g. Sager and Thomann 2017), disagreements persist about what actually constitutes a frame, particularly in relation to the involvement of frames within cognitive processes (Schön and Rein 1994; Stone 1998; Chong and Druckman 2006; Bacchi 2009; Cacciatore et al. 2016; van Hulst and Yanow 2016). However, we define frames with respect to properties of communications, treating frames as containing a set of meanings that organise objects and events in relation to a wider context of activity. They are external to the observer, directing one's attention to particular attributes of an object while deflecting attention from other aspects, meanings and orderings of reality contained within communications (Burke 1984, 111). Different observers may construe meanings in varied ways, but to the extent an observer can understand a language, frames obtain an autonomous coherence at least for a given time and place. This is particularly the case for broadcast media, which addresses a wide audience and is predicated on stabilities in meaning.

Although frames exist independent of particular advocates, Ferree and Merrill $(2000,456)$ have argued that linking frames with the agents who sponsor them is an important step towards providing a "more complex model of how people organise, use, and change their frames". We use the term "frame sponsor" to refer to actors, including individual persons, organisations and government entities, who support particular frames. The inclusion of frame sponsors helps respond to those who have criticised the MSF for its lack of a detailed notion of agency (e.g. Mukherjee and Howlett 2015). This is important because the decision by one frame sponsor to use a particular frame can place limits on the extent to which another frame sponsor can make use of the same frame on a contested policy issue; for example, if an industry actor concedes that their activities produce environmental harm then it may make it harder for others to deny that claim without first referring back to that industry actor's framing of the issue. Certain actors, such as government officials or industry representatives, may also dominate domestic policy debates with a common set of priorities, preconceptions and frames, whereas the media also tend to "index" their coverage to the range of frames provided by political elites (Tuchman 1978; Bennett 1990; Callaghan and Schnell 2001; Livingston and Bennett 2003). In the case of controversies such as the CSG debate, the presence of frame sponsors therefore becomes an important empirical question. Although the broadcast media may legitimate claims of different policy actors, we anticipate that political authorities and their frames will prove particularly consequential in news reporting given that they are the ones who have the power to effect legislative and regulatory change.

Changes in the presence of frame sponsors and the frames that they advocate may also have an impact on a problem window, its duration and eventual closure. Frame adoption approaches presume that actors may use a variety of frames over 
the course of a debate. In a contested field, frames may change if the prevailing frame does not gain enough traction and even those frames that are successful are likely to be countered before long. For example, Boscarino's (2009, 426) study of forestry policy found that interest groups "problem surf" by connecting "their solution of sustainable forestry to different policy problems" dependent on what is politically salient and likely to gain more traction. We expect that the introduction of new frames and new actors will prolong a problem window, whereas frame convergence between actors will close a problem window as convergence signals at least partial closure within a debate.

Finally, there is the question of what mechanisms cause problem windows to close. Kingdon (1997) argues that problem windows typically open in response to events. Events can disrupt existing patterns as they provide an opportunity for policy actors to "reframe" the narrative in their preferred direction (Tuchman 1978; Gamson and Modigliani 1989; Iyengar 1990; Benford and Snow 2000; Greenberg 2005). Frames can change when opponents attempt to capitalise on events that highlight a misfit between a frame and an unfolding event. However, elite convergence may also close a problem window. As the mediatisation of politics depends on the creation of a narrative of conflict (Blumler and Gurevitch 1995; Strömbäck 2008), convergence in elite frames removes the driver behind the news coverage. Last, elections may also serve as a point of closure by legitimating an agenda through resolution by an independent arbiter: the voting public. In sum, we expect that problem windows will close when conflict subsides.

\section{Research design}

This research design develops a novel approach for identifying problem windows that combines algorithmic methods with qualitative hand-coding. Algorithmic methods, such as topic models, enable researchers to cover large amounts of text that would be too resource-intensive to code using manual methods alone (Grimmer and Stewart 2013; Van Holt et al. 2013). These methods have already generated interest among public policy scholars (e.g. Klüver et al. 2015), and the approach developed here adds a qualitative dimension to that prior work. Combining algorithmic methods with hand-coding has advantages: it provides contextual sensitivity in interpreting the data (Aipperspach et al. 2006; Lewis et al. 2013; Hand and Hillyard 2014) and, just as computer-based analyses of texts are prone to making errors, human coders are prone to nonsystematic biases even when they use highly established coding schemes (Mikhaylov et al. 2012; GonzálezBailón and Paltoglou 2015).

Topic modelling has particular advantages for this study, as it can be used "diagnostically" to identify successive days of consistent news reporting on a particular topic. ${ }^{2}$ Although policy areas typically involve multiple dimensions (or "topics"), we are able to use topic models to construct problem windows within a single topic based on heightened and extended periods of topic prevalence within the news media (Nowlin 2016). Topic prevalence is operationalised in terms of model "thetas", which is a measure of the expected proportion of a topic in each document. Studies of framing have often used a simple article frequency count as a justification for "zooming in" on particular periods of time (e.g. Hurka and Nebel

\footnotetext{
${ }^{2}$ As a first cut on the data, we identified periods of highest reporting on CSG and found that they often included a mix of issues but did not contain a significant range of frames around a single topic.
} 
2013; Jaspal and Nerlich 2014; Metze 2014), but this does not always capture periods of heightened problematisation. For example, we found that brief stock market reports (several sentences long in the Finance pages) accounted for a high proportion of the total number of news articles published on CSG. These articles do not problematise the CSG issue but they still contribute to the article count. ${ }^{3}$ Consequently, using heightened periods of topic prevalence on a policy-related topic gives greater certainty that selected problem windows relate to actual periods of problematisation, rather than the other types of extraneous reporting that might be captured using a simple article frequency count.

Once a policy-related topic with a high overall topic prevalence had been identified, the topic proportions across all articles for that topic were summed and aggregated to identify problem windows: successive days of high topic prevalence. We retrieved and hand-coded all the news articles that fell between those dates for the presence of frames and frame sponsors. In short, we used the topic modelling "diagnostically" to identify problem windows and the qualitative analysis "analytically" to investigate the reasons why problem windows close.

The research design was split into four steps:

- Step 1: we captured the relevant data and prepared it for the topic modelling.

- Step 2: we ran the topic modelling, selected a 15-topic model and one policy-related topic from within that model.

- Step 3: we identified four problem windows from within the selected topic.

- Step 4: we hand-coded for the presence of frames and frame sponsors within the news articles published during the four problem windows identified in Step 3.

In Step 1, 2,414 newspaper articles were retrieved using the database Lexis/Nexis and the search term "coal seam gas". The search covered every news article (excluding "Letters to the Editor") that matched the search term in four Australian newspapers: The Australian, The Australian Financial Review, The Courier Mail (Brisbane) and the Sydney Morning Herald, between 1 January 2008 and 2 August 2016. Once retrieved, the articles underwent text preprocessing so that they could be used in the topic modelling. Topic models use "model vocabularies", which are the list of terms out of which patterns are identified to form topics. The topic models were unsupervised and prepared using Latent Dirichlet Allocation (LDA). LDA is a method commonly used in the study of journalism to analyse large volumes of news content and has been used by researchers studying contentious policy issues such as CSG (e.g. Blair et al. 2016; Günther and Quandt 2016; Jacobi et al. 2016; Bauer et al. 2017). It has also been shown to be effective at identifying topic distributions in newspapers when compared with hand-coding (Blair et al. 2016). ${ }^{4}$ The model was unsupervised because we approached the data not knowing ahead of time the topics or their relative proportions.

\footnotetext{
${ }^{3}$ It is also not always possible or desirable to exclude the Business/Finance section in its entirety. The Business/Finance section is not always identified as a separate subcategory in Lexis/Nexis, what counts as an article published in this section varies between newspaper outlets and this section can also contain fulllength articles that problematise the CSG issue.

${ }^{4}$ We validated our selection of the LDA model by comparing its results with an alternative spectral model, and they proved quite similar.
} 
Although LDA does not require any preanalysis, some text preprocessing is necessary to allow comparability of terms independent of their location within sentences. This step involves removing numbers, punctuation and standard stopwords (e.g. and, for, in, it), normalising text as lower case and reducing terms to their grammatical stems. Infrequently used terms and rarely used words are also removed to reduce unwanted noise and avoid creating topics that are only germane to one particular article. As a consequence, 625 very short articles were entirely eliminated and the topic modelling was conducted on the 1,789 reports that remained (see the Supplementary Information for further detail).

In Step 2, we ran the topic modelling (see Table 2 in the Supplementary Information for the results). It is a common feature of topic modelling to assume the number of topics before the modelling, and thus care needs to be taken when making this decision (Grimmer and King 2011). After running several tests (see below), a 15-topic model was selected within which several policy-related topics were identified (e.g. on the greenhouse effect, the mining tax and jobs and the economy). We then selected one policy-related topic related to "risk and regulation" as a basis for identifying the problem windows. We selected this topic for three reasons. First, the risk and regulation topic was the most prevalent topic among all of the topics - both those that concerned policy-related issues and those that did not (see Figure 1 in the Supplementary Information). From the 15 topics, risk and regulation was therefore identified as the most likely topic to exhibit the problem windows that were the particular motivation for this study and the research questions that informed it (Nowlin 2016, 319). ${ }^{5}$ Second, unlike other topics (e.g. the greenhouse effect), the risk and regulation topic is particular to the concerns surrounding CSG development. This makes the identification of discrete problem windows using algorithmic means more feasible as the topic contents are more likely be specific to the CSG controversy. Third, the risk and regulation topic provided a balance between having a topic that included enough problem windows to enable a thorough analysis and the time that it would take to hand-code the news articles that were selected through this process.

We interpreted the results from the topic modelling using the highest probability terms (those terms that are most frequent in the topic) and the "frex" terms (those terms that are most unique to the topic). When combined, these results define a topic according to both the salience of the terms that compose it and those terms that most distinguish one topic from the other topics present in the model. We gave each topic a name on this basis. The "highest probability terms" for our selected topic on risk and regulation were: said, gas, coal, seam, govern, nsw, water. "Coal", "seam" and "gas" appear among the highest probability terms as these are the terms defining the policy area. In addition, "govern" and "water" reference both the governing process and concerns about water pollution, one of the regulatory concerns raised by CSG development. Last, "nsw" denotes New South Wales, one of the geographic parameters bracketing this policy controversy. The "frex terms" were: frack, windsor, pilliga, buckingham, okan, tara and epa. Focussing on these terms, and discarding "okan", which seems to have multiple reference points, "frack" is a stemmed form of the term "fracking", which is a means of extracting CSG. The local CSG industry maintains that it does not frack, but opponents either

\footnotetext{
${ }^{5}$ Of course, this does not preclude the possibility of extending this study to include additional topics, address alternative research questions or analyse one of the other streams.
} 
challenge that claim or maintain that it is a distinction without a difference. Windsor is a reference to Tony Windsor, an independent MP. Pilliga is a forest area where CSG development has been hotly contested in northern NSW. Tara is a location in Queensland where there is a CSG production facility. The EPA is the NSW Environmental Protection Agency, and Buckingham is a Green party MP. Although these data show the close association of particular actors with the topic, actors can frame the terms within a topic in a variety of ways that express either opposition or support for CSG.

There is no single diagnostic test to evaluate topic models, and thus we conducted several different tests to validate our choices. First, we measured and then compared the semantic coherence and exclusivity of models ranging from 10 to 20 topics (see Table 1 in the Supplementary Information). Semantic coherence measures whether the terms in a topic model appear with a high degree of terminological cooccurrence, whereas exclusivity measures the level of differentiation between the topics. The results from these tests show that a 15-topic model has the second highest semantic coherence (-85.10190) and a higher exclusivity (9.623557) than the 10-topic model. This suggests that a 15-topic model achieves an appropriate balance between the extremes of either mixing distinct issues together in the same topic, which would reduce topic exclusivity, or artificially parsing more topics than the underlying text would warrant. Second, we tested for the robustness of the risk and regulation topic by running models for 10, 15 and 20 topics. The risk and regulation topic was the most prevalent topic in all three models, which helps confirm that the appearance of this topic is not spurious. Finally, we also used the qualitative analysis to confirm the risk and regulation topic and its overall coherence as per the approach taken by others (e.g. Blair et al. 2016; Roberts et al. 2016). Our coders were not told about the topic, and the selected articles contained more than our single topic of interest; however, a thematically salient discussion and clear narrative concerning the risks associated with CSG was present in all four problem windows. Thus, we were able to combine a theoretical understanding of the object of analysis with small $\mathrm{N}$ comparison between the model results and the texts themselves.

In Step 3, four problem windows were constructed from within the risk and regulation topic. Problem windows are demarcated temporally, and thus it was necessary to develop a measure of topic prevalence as a function of time. The prevalence of the risk and regulation topic was summed on a daily basis, and a seven-day rolling mean of its daily topic prevalence was calculated to account for media cycles. ${ }^{6}$ Figure 1 presents the results from this analysis where the $y$-axis shows the summated proportions across all documents, aggregated daily. As the underlying data reflect the proportions of each topic in each document, and there is no limit on the number of articles per day, this metric has no logical upper bound.

The data in Figure 1 are quite "noisy", necessitating criteria by which problem windows could be systematically identified and differentiated from other time points. We addressed this by summing the topic prevalence at the article level (model thetas) to create a measure of both the distribution of this topic across articles and the intensity of the focus on this topic in any one particular article.

\footnotetext{
${ }^{6}$ Most of our newspaper outlets did not publish weekend editions and none of our newspapers published more often than daily. A rolling mean was used to reduce the noise by averaging out the data for any given day.
} 


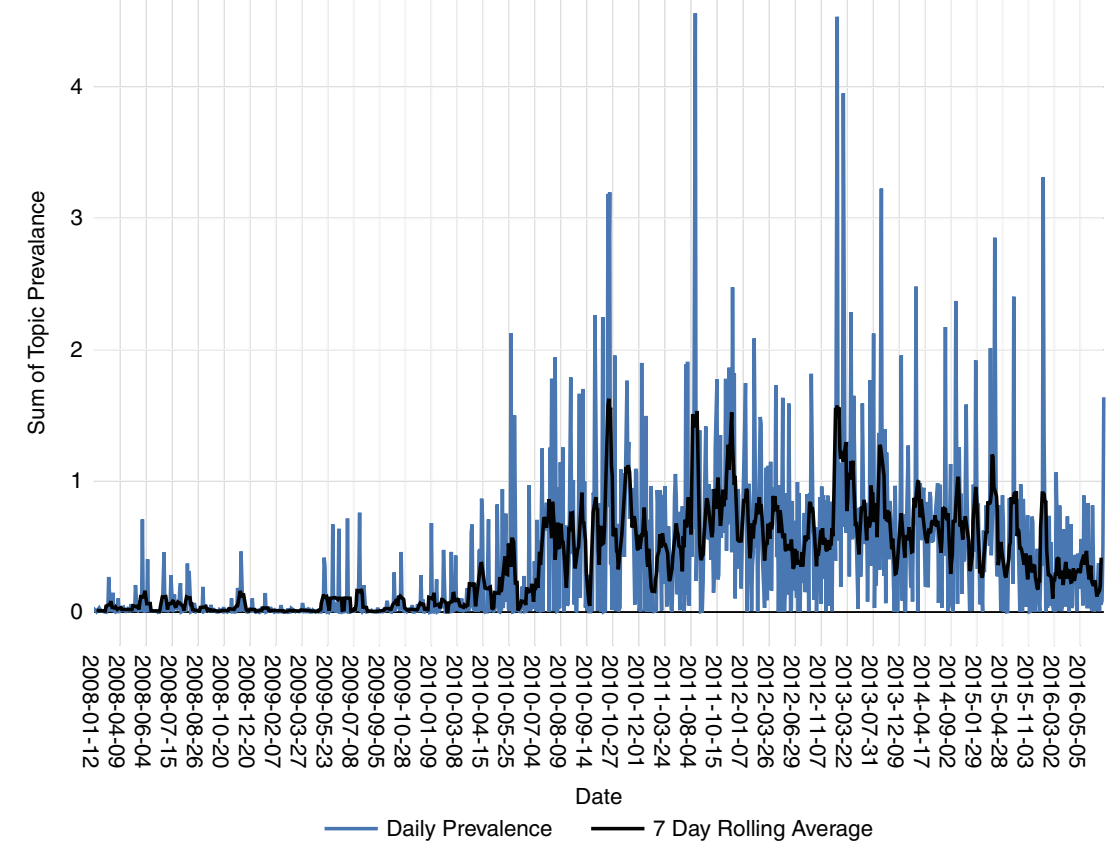

Figure 1. Risk and regulation over time.

Hence, a topic featuring marginally in many articles might still have the same prevalence on a given day as a topic that features heavily in only two articles. We then ordered the results from the day with the highest topic prevalence through to the day with the lowest topic prevalence. We constructed the problem windows by looking within the top 100 days of topic prevalence for at least three days of successive media attention with no more than one day in-between. Where this existed, we took it as evidence of sustained reporting on the topic: that is both an initial increase in the topic's prevalence and a follow-up in interest over successive days. The one-day gap was permitted to allow for other news outlets to pick up a story covered initially by a rival, which is sign of the continuing relevance of the issue. Table 1 presents the results from Step 3. The total topic prevalence in Table 1 refers to the summated topic prevalence across all articles between the date range specified for that window. The four problem windows have been named after the major news story reported in that window.

We validated our selection of problem windows by running several tests. First, we attempted to construct a fifth problem window. This was only possible within the 200 top days of reporting. The window was also only three days long, and did not revolve around a concrete problem situation. ${ }^{7}$ Second, the topic prevalence was substantially lower than for the other four windows. $t$-tests confirmed that the topic concentrations on a daily basis during our problem windows were substantially higher than during a hypothetical fifth window and that these differences

\footnotetext{
${ }^{7}$ Reporting during the fifth problem window included varied commentaries on lessons learnt from Queensland Australia, a report from Victoria Australia and a Labor strategy to embarrass the Liberal party.
} 
Table 1. Problem windows

\begin{tabular}{lcccc}
\hline Problem Window & Date Range & Articles & $\begin{array}{c}\text { Total Topic } \\
\text { Prevalence }\end{array}$ \\
\hline Problem window 1: industry development & $13 / 10 / 2010-29 / 10 / 2010$ & 47 & 12.72901 \\
\hline Problem window 2: land access & $03 / 08 / 2011-22 / 08 / 2011$ & 26 & 14.39230 \\
\hline Problem window 3: buffer zone regulation & $16 / 02 / 2013-03 / 03 / 2013$ & 16 & 9.78787 \\
\hline Problem window 4: NSW state election & $20 / 03 / 2015-04 / 04 / 2015$ & 21 & 9.44679 \\
\hline Problem window 5: variety of commentaries & 22/09/2013-30/09/2013 & 7 & 5.764 \\
\hline
\end{tabular}

were statistically significant $(t=4.253, \mathrm{p}<0.000)$. Finally, we charted the daily topic prevalence values in the four problem windows, which show a clear period of problem build-up and then decline in topic prevalence corresponding to the emergence, climax and closure of the problem window (see Figures $2 \mathrm{a}-2 \mathrm{~d}$ in the Supplementary Information).

In Step 4, we hand-coded the selected articles $(n=110)$ in Table 1 for the presence of frames and frame sponsors. We included all the news articles published within the date range covered by each problem window so that we could explore whether a problem window closes when a new issue intrudes. We also added a lead and lag of three days to capture the emergence and closure of a topic, including any transformation in the frames and frame sponsors. Frames were identified as coherent positions attached to an actor, which provide a description of a situation organised with respect to a normative position (for or against CSG) and a range of action. We also hand-coded for the presence of frame sponsors: entities who advocate a particular frame (e.g. individuals, organisations or position titles), as well as their abstract representations (e.g. "protestors" or "industry groups") (Carragee and Roefs 2004; Gamson 2004). We coded every frame to an actor whether they were quoted directly or paraphrased. ${ }^{8}$ We then associated frame sponsors with particular social groupings. We used this coding to track the changing presence of frame sponsors, as well as similarities or differences in the frames that they were using. We checked for intercoder reliability on a random sample of $10 \%$ of the articles using the $\kappa$ coefficient (Neuendorf 2002). The result from this test was 0.63 , which is on the higher end of the fair to good agreement range (0.4-0.75) (Hayes and Krippendorff 2007). These results match the findings from similar comparisons undertaken elsewhere (e.g. Klüver 2009; Klüver et al. 2015; Blair et al. 2016).

\section{Problem windows and the CSG debate in Australia}

We present our findings in two sections. First, we detail the aggregate results and then we discuss the four problem windows in turn. In total, the 110 selected news articles contained a total of 485 frames and 350 unique frame sponsor mentions (there are more frames than unique frame sponsor mentions because a frame sponsor may deploy more than one frame in a single mention). Nine categories of frame sponsors and nine categories of frames were identified during the analysis.

\footnotetext{
${ }^{8} \mathrm{~A}$ direct quote is clearly different from having one's words rendered by a journalist, but this distinction is incidental to this analysis.
} 
Table 2. Frame categories

\begin{tabular}{|c|c|}
\hline \multicolumn{2}{|c|}{ Anti-CSG frame categories } \\
\hline High risk & $\begin{array}{l}\text { CSG is a little-understood, high-risk industry } \\
\text { The science and safety surrounding CSG is unresolved. The precautionary } \\
\text { principle should apply } \\
\text { The risks and potential impact of CSG on the environment, other industries } \\
\text { and human health are too high }\end{array}$ \\
\hline Farmers and land & $\begin{array}{l}\text { The CSG industry will have a negative impact on farmers, agriculture and } \\
\text { landscapes } \\
\text { The CSG industry risks prime agricultural land and threatens farmers' property } \\
\text { rights } \\
\text { Farmers need to be adequately compensated }\end{array}$ \\
\hline Water & $\begin{array}{l}\text { The CSG industry risks contaminating and depleting the groundwater supply } \\
\text { The extraction of large amounts of water from coal seams, its management } \\
\text { and its effects remain unanswered }\end{array}$ \\
\hline Community & $\begin{array}{l}\text { CSG will increase tensions and have a negative impact on communities } \\
\text { Community concerns are not being adequately addressed, including the } \\
\text { pressure that the industry will place on house prices and local infrastructure }\end{array}$ \\
\hline $\begin{array}{l}\text { Business and } \\
\text { politics }\end{array}$ & $\begin{array}{l}\text { The CSG industry has political, economic and cultural power within } \\
\text { government } \\
\text { The CSG industry is colluding with the government } \\
\text { The energy industry will always be favoured over the agricultural industry and } \\
\text { local communities }\end{array}$ \\
\hline \multicolumn{2}{|c|}{ Pro-CSG frame categories } \\
\hline Managed risk & $\begin{array}{l}\text { CSG is a well-understood, low-risk industry } \\
\text { The CSG industry is well regulated or excessively regulated } \\
\text { Any negative impacts from CSG are easily managed }\end{array}$ \\
\hline Jobs and growth & $\begin{array}{l}\text { The CSG industry benefits the economy and provides jobs } \\
\text { CSG can coexist with other industries } \\
\text { The economic benefits from CSG are local, as well as national }\end{array}$ \\
\hline Energy & $\begin{array}{l}\text { CSG is a clean power source } \\
\text { CSG can ensure future energy security } \\
\text { CSG will help keep energy prices low }\end{array}$ \\
\hline Governance & $\begin{array}{l}\text { The subsidiarity principle means that regulatory responsibility for CSG should } \\
\text { reside at the lowest possible level (and most often with the states) } \\
\text { Governments have the capacity to effectively manage and govern the CSG } \\
\text { industry }\end{array}$ \\
\hline
\end{tabular}

$\mathrm{CSG}=$ coal seam gas

The nine frame categories consisted of five anti-CSG frames $[n=258$ split between high risk $(n=107)$, farmers and land $(n=58)$, water $(n=38)$, community $(n=32)$ and business and politics $(n=23)]$ and four pro-CSG frames $[n=201$ split between managed risk $(n=103)$, jobs and growth $(n=46)$, energy $(n=38)$ and governance $(n=14)]$. We also included an "other" category $(n=26)$ for any frames that did not match one of the nine major frame categories identified here. Although some of these frames draw upon overlapping premises, we differentiate them as they provide logically distinct grounds for supporting or opposing CSG development. Table 2 lists the nine categories of frames and their key features. 
Table 3. Frame sponsors

\begin{tabular}{|c|c|}
\hline \multicolumn{2}{|c|}{ Anti-CSG frame sponsors } \\
\hline Farmers & Farmers mentioned by name or by generic reference to the "farmers" \\
\hline Anti-CSG groups & Groups and social movements opposed to CSG and their spokespeople \\
\hline Farming lobbyists & Farming lobby organisations and their spokespeople \\
\hline \multicolumn{2}{|l|}{ Pro-CSG frame sponsors } \\
\hline Energy companies & Energy companies and their spokespeople \\
\hline Energy lobbyists & Energy and mining lobbyists, and their spokespeople \\
\hline Trade unions & Trade unions and their spokespeople \\
\hline \multicolumn{2}{|l|}{ Other frame sponsors } \\
\hline State politicians & $\begin{array}{l}\text { Members of a State Parliament, government ministers and members of } \\
\text { the official opposition, state level political parties and candidates } \\
\text { running for office in the state election }\end{array}$ \\
\hline Federal politicians & $\begin{array}{l}\text { Members of the Federal Parliament, government ministers and members } \\
\text { of the official opposition, federal level political parties and candidates } \\
\text { running for office in the federal election }\end{array}$ \\
\hline Community members & $\begin{array}{l}\text { Community members mentioned by name or by generic reference such } \\
\text { as "locals" or "residents of Tara" }\end{array}$ \\
\hline Other & Individuals and groups that do not fit into any of the categories above \\
\hline
\end{tabular}

$\mathrm{CSG}=$ coal seam gas.

Three frame sponsors consistently adopted anti-CSG frames $[n=80$ split between farmers $(n=36)$, anti-CSG groups $(n=25)$ and farming lobbyists $(n=19)]$ and pro-CSG frames, respectively $[n=82$ split between energy companies $(n=39)$, energy lobbyists $(n=32)$ and trade unions $(n=11)]$. A further three frame sponsors $[n=139$ split between state politicians $(n=71)$, federal politicians $(n=61)$ and community members $(n=7)]$ adopted a mix of anti- and pro-CSG frames. We also included an "other" category $(n=49)$ for any frame sponsors who did not match one of the nine major frame sponsors. They also sponsored a mix of anti- and pro-CSG frames. Table 3 lists the nine major frame sponsors and their key features.

The first problem window - industry development - contained 128 frames and 89 unique frame sponsors. Two news stories dominated this problem window during a 16-day period starting from Wednesday 13 October 2010. The first news story centred on a press release in which a CSG company announced the detection of Benzene, Toluene, Ethylbenzene and Xylene (BTEX) chemicals in its exploration wells ( $n=11$ articles). This was followed two days later by a news story concerning the Federal Environment Minister's approval of a LNG export facility on Curtis Island ( $n=16$ articles). Five articles reported on these two stories in the same piece.

The major frame sponsors in this problem window included farmers $(n=17)$, farming lobbyists $(n=12)$, anti-CSG groups $(n=10)$ and energy companies $(n=13)$. Other frame sponsors were present $(n=31)$ but they were mentioned less than ten times. Anti-CSG frames $(n=83)$ dominated over pro-CSG frames $(n=43)$. The three 
dominant anti-CSG frames were high risk $(n=46)$, water $(n=15)$ and farmers and land $(n=13)$, whereas the two dominant pro-CSG frames were managed risk $(n=28)$ and jobs and growth $(n=14)$. Although the water frame was present across both news stories, the high risk and jobs and growth frames featured more heavily in the LNG story. Most frames emphasised the environmental and social risks of CSG and/or the need for tighter regulation. In short, this was a problem window dominated by anti-CSG frame sponsors $(n=45)$ and anti-CSG frames $(n=83)$. The problem window closes five days after the news story on the BTEX spill and three days after the government's announcement approving the LNG export facility. The CSG industry's managed risk frame appears to have been effective in closing the problem window, including its repeated reassurances that the risks associated with the spill were manageable and that the "community should have confidence in the processes we've put in place - as soon as there are issues we inform the regulator" (The Australian 2010). The bipartisan political support for the LNG export facility and its timed announcement also helps explain why this problem window closed.

The second problem window - land access - contained 145 frames and 111 unique frame sponsors. Two news stories dominated this problem window in a 19-day period from Wednesday 3 August 2011. The first news story concerned otherwise unconnected events such as the announcement of a parliamentary inquiry into CSG, a public meeting held by an energy lobby group and a group of anti-CSG protesters "gatecrashing" an industry conference ( $n=12$ articles). The media used these protests to report more widely on community concerns towards CSG. This problem window was also extended by a second news story concerning comments made in a radio interview by the former Opposition Leader, Tony Abbott, in which he argued that farmers' property rights needed greater protection ( $n=11$ articles). The interview was interpreted as a departure from the bipartisan political support that had been shown towards the CSG industry, which helped spark a political debate about the role of the federal government in regulating CSG. Anti-CSG parties, such as the Greens, used Abbott's interview to argue for more federal regulation and stronger land access requirements.

The major frame sponsors in this problem window were federal politicians $(n=41)$ and state politicians $(n=21)$ who both used a mix of pro- and anti-CSG frames. There was a fairly even split between anti-CSG $(n=24)$ and pro-CSG frame sponsors $(n=18)$, including agricultural voices $(n=19)$ and the energy sector $(n=18)$, but anti-CSG frames $(n=81)$ were present more than pro-CSG frames $(n=59)$. Abbott's radio interview led to a significant rise in the farmers and land frame. There was a split between Green politicians who sponsored high-risk frames and the Government who tended to sponsor the managed risk and energy frames. Other prominent frame sponsors included state politicians, agricultural voices and energy lobbyists and companies. State politicians did not engage with the land and access frame but did sponsor the high risk, managed risk, jobs and growth and community frames. Agricultural voices consistently sponsored the water frame and the farmers and land frame, whereas energy sector voices sponsored the energy, managed risk and jobs and growth frames.

In terms of frame sponsors, the reporting notably shifts towards politicians ( $n=52$ over a five-day period) in the week after Abbott's radio interview. Other frame sponsors ( $n=22$ over a five-day period), both pro- and anti-CSG, are marginalised during this period. The problem window closes once federal 
politicians converge around a governance frame, which places responsibility for CSG regulation with the states. Thus, elite frame convergence among federal politicians' closes off debate and prevents other frame sponsors from extending the problem window's duration.

The third problem window - buffer zone regulation - contains 60 frames and 43 unique frame sponsor mentions in a 13-day period from Saturday 16 February 2013. A government announcement that it would introduce a $2 \mathrm{~km}$ "no go zone" for CSG exploration adjacent to urban areas and prime horse/winery land dominated this problem window. Most of the coverage of this story took place in the two days before and after the announcement ( $n=9$ articles). There was one other minor news story in this problem window ( $n=2$ articles).

The major frame sponsors in this problem window included trade unions $(n=9)$, state politicians $(n=8)$, federal politicians $(n=7)$ and the energy sector $(n=8)$. The presence of trade unions is related to the minor news story, whereas the three other frame sponsors $(n=23)$ all relate to the new buffer zone regulation. Anti-CSG $(n=24)$ and pro-CSG frames $(n=31)$ were fairly evenly distributed, but politicians and the energy sector heavily dominated the frame sponsorship. Although state politicians sponsored high risk and community frames to justify the new regulation, the energy sector sponsored frames that emphasised energy (security), jobs and growth. Pro-CSG frame sponsors used the energy frame to draw attention to NSW's looming energy crisis and the jobs and growth frame to focus on the industry's economic potential.

The final problem window - NSW state election - contains 152 frames and 107 unique frame sponsor mentions in a 15-day period from Friday 20 March 2015. The major news story in this problem window concerned the NSW state election, which took place on 28 March 2015 ( $n=12$ articles). CSG exploration was a key election issue in several marginal seats where longstanding incumbents from the National party were seen as being under potential threat from anti-CSG candidates, including the Greens and other Independents. The NSW Labor party also took an anti-CSG position by announcing its intention to ban Santos's controversial Narrabri Gas Project, one of only two serious CSG proposals in the state at the time. There were five other articles in this problem window.

The major frame sponsors in this problem window include state politicians $(n=39)$, energy lobbyists $(n=10)$, energy companies $(n=13)$ and federal politicians $(n=8)$. Notably, anti-CSG frame sponsors $(n=8)$ are relatively marginalised compared with pro-CSG frame sponsors $(n=27)$ despite anti-CSG frames $(n=70)$ and pro-CSG frames $(n=68)$ remaining fairly balanced. The "other" category $(n=25)$ is relatively high and includes a range of actors from musicians to actors and radio talk-show hosts to ex-public servants. On the presence and distribution of frames, risk-based frames $(n=72)$ are the most important. Managed risk frames $(n=41)$ are mainly sponsored by the energy sector that presents CSG as a low-risk technology that has local community support. Opposition to CSG comes from "outsiders" who only want to "make trouble" by "politicising" the decision-making process. Conversely, high-risk and community frames are mainly sponsored by state politicians, particularly the Greens and Labor. The business and politics frame $(n=10)$ - which focusses on distrust and collusion between industry and the government - also gains prominence in this problem window for the first time. New frame sponsors, such as Simone Marsh, an ex-public servant whistle-blower, and Dayne Pratzky, an activist/actor in the movie Frackman, sponsor this frame. 
The problem window closes three days after the election. Although the anti-CSG movement gains votes in several swing states, they fail to achieve an overall win and the problem window closes. There are two notable differences between this problem window and the others: first, a greater diversity in frame sponsors and, second, an even distribution between anti- and pro-CSG frames despite a larger presence of pro-CSG frame sponsors.

\section{Discussion: why do problem windows close?}

The results from this analysis suggest that problem windows generally close in response to institutionalised events and actions by formal political authorities. These events and actions lead to the closure of problem windows because they decisively reshape the context of problematisation, resolving or undermining the motivational grounds on which the problem window first emerged. Although the four problem windows detail distinct actions, they all function in the same way: the problem windows close once the provocation to continue the conflict has receded and there is no further interest in continuing to report on the original story that had provoked the initial contestation. These findings suggest that nonelite policy actors will find it challenging to open a problem window independently from either an action or intervention by a political authority or an institutionalised event.

We can also identify three specific mechanisms, which all point to how press coverage is primarily motivated by conflict. The first mechanism, elite frame convergence, occurs when an issue becomes noncontentious and a problem window closes because elites come to share a common framing of the issue. The second problem window provides an example of this mechanism at work. Abbott's radio interview broke with the established bipartisan policy and led to frame divergence between the Government and Opposition. However, the Government and Opposition's subsequent convergence around a governance frame effectively closed the problem window.

Problem windows also closed following public statements. In general, these problem windows are relatively short-lived because they are limited to the announcement itself. The introduction of a new buffer zone regulation in the third problem window provides an example of this mechanism. The new regulation was announced and state politicians were given an opportunity to justify the change. Without a new news story, the problem window closes. However, industries can also use public statements as an attempt to get ahead of a controversy and close off debate. In our analysis, this is illustrated by the BTEX press release, which successfully managed to close a problem window by promoting consistent and reassuring frames around managed risk. The company got "ahead of the story" by preempting public opposition and developing a response to it.

Our final mechanism is elections. Here, problem windows close because they provide democratic legitimation for particular issue framings in a space of contestation. The state election was branded as a "referendum" on the "future of CSG". Although anti- and pro-CSG frames were fairly evenly distributed, anti-CSG groups were largely marginalised from the debate by state and federal politicians who sponsored anti-CSG frames. The problem window closed shortly after the election result when it was reported that the anti-CSG movement made important gains but not enough to win.

Our finding that the operation of problem windows is closely linked to the ability to control or prolong a controversy suggests opportunities for further 
research. First, a comparative examination of other policy domains could be used to further delimit the conditions under which problem windows persist and close. Second, the methodological approach outlined here could be used to compare problem windows in other venues such as social media, written submissions to parliamentary inquiries and government reports. The broadcast news media remains important, but social media is also a crucial communication platform and written submissions present frame sponsors with an opportunity to outline their position on an issue at length. Studying other venues may also present opportunities to analyse the norms within different media systems (Hallin and Mancini 2004). This study found a more or less equal number of pro- and anti-CSG frames, but there were also times when new frames and new frame sponsors had more of an opportunity to enter into the debate (e.g. during elections). The news media's tendency towards "balanced coverage" in which competing arguments are presented, the time and resource pressures of the news room and how journalists report issues more generally may both shape the conclusions of this study but also present an opportunity for comparison between how problem windows operate in the news media compared with other communication channels where similar norms and practices do not apply. Interviews may also present opportunities to explore problems that are being discussed out of public purview, as well as issues that the news media have not reported on.

\section{Conclusion}

This article has examined how frames change within and between four problem windows or, to put it differently, both within continuous contexts and diachronically across contexts. It has done so through an innovative combination of qualitative and digital methods. By focussing on a specific debate in Australia, we have been able to control for the context at any given time. Our findings indicate that problem windows close when the grounds for problematisation cease to exist. A controversy generated by a suspicion may cease at the time the suspicion is either confirmed or demonstrably denied.

The finding that elite actions and elections close problem windows points to their particular role in dialogically reshaping the grounds that gave rise to contestation in the first place. Both industry and political elites played a much larger role in the discourse over CSG than the voices of activists. Elite actions and statements play a larger role given their functions as decisionmakers regarding policy, policy leadership or business activity. These findings are consistent with Bennett's "indexing" theory that news reporting tends to be indexed to the terms of elite actors and this finding is likely generalisable as the indexing theory has held up over time and across varied contexts (Bennett 1990; Livingston and Bennett 2003). Whatever contestation has been created by civil society actors, elite reaction or an electoral result can also have the effect of dissipating the controversy. Although movements may make use of new digital communications tools, their capacity to influence broadcast media debates appears more limited and dependent on partnering with like-minded elites.

We have also been able to show that problem windows close once the original grounds for why they opened no longer pertain even if the issues that opened the problem window in the first place transcend its very closure. An example from this study is the state election where an election contest opened a problem window. 
Although this is a finding consistent with the MSF literature (e.g. Birkland 1997, 1998), the election result also marked the end of the problem window because the initial reason for the debate was no longer present even though concerns about CSG continued to persist beyond the campaign period. This shows how context is integral to the analysis of problem windows.

These findings also have important implications for the MSF because they help us understand how and why problem streams evolve and the factors that influence policy change more broadly. The problem stream is one of three streams and the MSF posits that policy change occurs when coupling occurs across all three streams. By better understanding how the problem stream evolves, we can begin to contribute to a broader understanding of how the three streams interact and couple with each other to generate policy change. This article represents a first step in that direction.

Supplementary materials. To view supplementary material for this article, please visit https://doi.org/ $10.1017 / \mathrm{S} 0143814 \mathrm{X} 18000132$

Acknowledgements. The authors acknowledge funding from the Australian Research Council (DP150103615), as well as the extremely helpful comments and suggestions on earlier versions of this article from Dr Francesco Balio and Dr Matt Wood, the journal's four reviewers and the journal's Field Editor, Professor Fabrizio Gilardi.

\section{References}

Aipperspach R, Rattenbury TL, Woodruff A, Anderson K, Canny JF and Aoki P (2006) Ethno-Mining: Integrating Numbers and Words from the Ground Up. Published October 2006 by Electrical Engineering and Computer Sciences, University of California, Berkeley, CA.

The Australian (2010) LNG wells threaten Murray. The Australian, 21 October, p. 5.

Bacchi C (2009) Analysing Policy: What's the Problem Represented To Be? Frenchs Forest, NSW: Pearson Higher Education.

Bauer PC, Barberá P, Ackermann K and Venetz A (2017) Is the Left-Right Scale a Valid Measure of Ideology? Political Behavior 39(3): 553-583.

Baumgartner FR, De Boef SL and Boydstun AE (2008) The Decline of the Death Penalty and the Discovery of Innocence. Cambridge: Cambridge University Press.

Baumgartner FR and Jones BD (1993) Agendas and Instabilities in American Politics. Chicago, IL: University of Chicago Press.

Béland D (2016) Kingdon Reconsidered: Ideas, Interests and Institutions in Comparative Policy Analysis. Journal of Comparative Policy Analysis 18(3): 228-242.

Béland D and Howlett M (2016) The Role and Impact of the Multiple-Streams Approach in Comparative Policy Analysis. Journal of Comparative Policy Analysis 18(3): 221-227.

Benford RD and Snow DA (2000) Framing Processes and Social Movements: An Overview and Assessment. Annual Review of Sociology 26, 611-639.

Bennett WL (1990) Toward a Theory of Press-State Relations in the United States. Journal of Communication 40(2): 103-125.

Birkland TA (1997) After Disaster: Agenda Setting, Public Policy and Focusing Events. Washington, DC: Georgetown University Press.

Birkland TA (1998) Focusing Events, Mobilization, and Agenda Setting. Journal of Public Policy 18(1): 53-74.

Blair BD, Weible CM, Heikkila T and Evensen D (2016) Comparing Human and Automated Coding of News Articles on Hydraulic Fracturing in New York and Pennsylvania. Society and Natural Resources 29(7): 880-884.

Blumler J and Gurevitch M (1995) The Crisis of Public Communication. New York: Routledge.

Bomberg E (2015) Shale We Drill? Discourse Dynamics in UK Fracking Debates. Journal of Environmental Policy \& Planning 19(1): 72-88.

Boscarino JE (2009) Surfing for Problems: Advocacy Group Strategy in U.S. Forestry Policy. Policy Studies Journal 37(3): 415-434. 
Boscarino JE (2016) Setting the Record Straight: Frame Contestation as an Advocacy Tactic. Policy Studies Journal 44(3): 280-308.

Boykoff MT and Boykoff JM (2004) Balance as Bias: Global Warming and the US Prestige Press. Global Environmental Change 14(2): 125-136.

Burke K. (1984) Attitudes Toward History. Berkeley, CA: University of California Press.

Cacciatore MA, Dietram AS and Iyengar S (2016) The End of Framing as We Know It ... and the Future of Media Effects. Mass Communication and Society 19(1): 7-23.

Cairney P and Jones MD (2016) Kingdon's Multiple Streams Approach: What is the Empirical Impact of this Universal Theory? Policy Studies Journal 44(1): 37-58.

Callaghan K and Schnell F (2001) Assessing the Democratic Debate: How the News Media Frame Elite Policy Discourse. Political Communication 18(2): 183-213.

Carragee KM and Roefs W (2004) The Neglect of Power in Recent Framing Research. Journal of Communication 54(2): 214-233.

Carvalho A (2007) Ideological Cultures and Media Discourses on Scientific Knowledge: Rereading News on Climate Change. Public Understanding of Science 16(2): 223-243.

Chong D and Druckman JN (2006) Framing Theory. Annual Review of Political Science 10, 103-126.

De Bruycker I (2016) Framing and Advocacy: A Research Agenda for Interest Group Studies. Journal of European Public Policy 24(5): 775-787.

Downs A (1972) Up and Down with Ecology-the Issue-Attention Cycle. The Public Interest 28, $38-50$.

Evensen DT, Clarke CE and Stedman RC (2014) A New York or Pennsylvania State of Mind: Social Representations in Newspaper Coverage of Gas Development in the Marcellus Shale. Journal of Environmental Studies and Sciences 4(1): 65-77.

Fawcett P and Wood M (2017) Depoliticization, Meta-Governance, and Coal Seam Gas Regulation in New South Wales. In Fawcett P, Flinders M, Hay C and Wood M (eds.), Anti-Politics, Depoliticization, and Governance. Oxford: Oxford University Press, 217-243.

Ferree MM and Merrill DA (2000) Hot Movements, Cold Cognition: Thinking About Social Movements in Gendered Frames. Contemporary Sociology 29(3): 454-462.

Gamson WA (2004) Bystanders, Public Opinion, and the Media. In Snow DA, Soule SA and Kriesi H (eds.), The Blackwell Companion to Social Movements. New York: Blackwell, 242-261.

Gamson WA and Modigliani A (1989) Media Discourse and Public Opinion on Nuclear Power: A Constructionist Approach. American Journal of Sociology 95(1): 1-37.

Gamson WA and Wolfsfeld G (1993) Movements and Media as Interacting Systems. The Annals of the American Academy of Political and Social Science 528, 114-125.

González-Bailón S and Paltoglou G (2015) Signals of Public Opinion in Online Communication: A Comparison of Methods and Data Sources. The Annals of the American Academy of Political and Social Science 659, 95-107.

Greenberg JH (2005) Language Universals: With Special Reference to Feature Hierarchies. Berlin: Mouton de Gruyter.

Grimmer J and King G (2011) General Purpose Computer-Assisted Clustering and Conceptualization. Proceedings of the National Academy of Sciences of the United States of America 108(7): 2643-2650.

Grimmer J and Stewart B (2013) Text as Data: The Promise and Pitfalls of Automatic Content Analysis Methods for Political Texts. Political Analysis 21(3): 267-297.

Günther E and Quandt T (2016) Word Counts and Topic Models. Digital Journalism 4(1): 75-88.

Hajer MA and Wagenaar H (2003) Deliberative Policy Analysis: Understanding Governance in the Network Society. Cambridge: Cambridge University Press.

Hallin DC and Mancini P (2004) Comparing Media Systems: Three Models of Media and Politics. Cambridge: Cambridge University Press.

Hand M and Hillyard S (eds) (2014) Big Data?: Qualitative Approaches to Digital Research. Volume 13 Bingley: Emerald Group Publishing.

Hayes AF and Krippendorff K (2007) Answering the Call for a Standard Reliability Measure for Coding Data. Communication Methods and Measures 1(1): 77-89.

Howlett M (1998) Predictable and Unpredictable Policy Windows: Institutional and Exogenous Correlates of Canadian Federal Agenda-Setting. Canadian Journal of Political Science/Revue canadienne de science politique 31(3): 495-524. 
Howlett M, McConnell A and Perl A (2015) Streams and Stages: Reconciling Kingdon and Policy Process Theory. European Journal of Political Research 54(3): 419-434.

Hurka S and Nebel K (2013) Framing and Policy Change After Shooting Rampages: A Comparative Analysis of Discourse Networks. Journal of European Public Policy 20(3): 390-406.

Iyengar S (1990) Framing Responsibility for Political Issues: The Case of Poverty. Political Behavior 12(1): $19-40$.

Jacobi C, van Atteveldt W and Welbers K (2016) Quantitative Analysis of Large Amounts of Journalistic Texts Using Topic Modelling. Digital Journalism 4(1): 89-106.

Jaspal R and Nerlich B (2014) Fracking in the UK Press: Threat Dynamics in an Unfolding Debate. Public Understanding of Science 23(3): 348-363.

Jones MD, Peterson HL, Pierce JJ, Herweg N, Bernal A, Raney HL and Zahariadis N (2016) A River Runs Through it: A Multiple Streams Meta-Review. Policy Studies Journal 44(1): 13-36.

Kingdon JW (1997) Agendas, Alternatives, and Public Policies, 2nd ed. New York: Longman.

Klüver H (2009) Measuring Interest Group Influence Using Quantitative Text Analysis. European Union Politics 10(4): 535-549.

Klüver H, Mahoney C and Opper M (2015) Framing in Context: How Interest Groups Employ Framing to Lobby the European Commission. Journal of European Public Policy 22(4): 481-498.

Knaggård Å (2015) The Multiple Streams Framework and the Problem Broker. European Journal of Political Research 54(3): 450-465.

Kriesi H (1995) New Social Movements in Western Europe: A Comparative Analysis. Minneapolis, MN: University of Minnesota Press.

Lewis SC, Zamith R and Hermida A (2013) Content Analysis in an Era of Big Data: A Hybrid Approach to Computational and Manual Methods. Journal of Broadcasting \& Electronic Media 57(1): 34-52.

Livingston S and Bennett WL (2003) Gatekeeping, Indexing, and Live-Event News: Is Technology Altering the Construction of News? Political Communication 20(4): 363-380.

Metze T (2014) Fracking the Debate: Frame Shifts and Boundary Work in Dutch Decision Making on Shale Gas. Journal of Environmental Policy \& Planning 19(1): 35-52.

Meyer DS (2004) Protest and Political Opportunities. Annual Review of Sociology 30(1): 125-145.

Mikhaylov S, Laver M and Benoit KR (2012) Coder Reliability and Misclassification in the Human Coding of Party Manifestos. Political Analysis 20(1): 78-91.

Mukherjee I and Howlett M (2015) Who is a Stream? Epistemic Communities, Instrument Constituencies and Advocacy Coalitions in Public Policy-Making. Politics and Governance 3(2): 65-75.

Neuendorf KA (2002) The Content Analysis Guidebook. London: Sage.

Nisbet MC and Huge M (2006) Attention Cycles and Frames in the Plant Biotechnology Debate: Managing Power and Participation Through the Press/Policy Connection. Harvard International Journal of Press/Politics 11(1): 3-40.

Nowlin MC (2016) Modelling Issue Definitions Using Quantitative Text Analysis. Policy Studies Journal 44(3): 309-331.

NSW Parliamentary Library (2013) Gas: Resources, Industry Structure and Domestic Reservation Policies. Briefing Paper No. 12/2013, NSW Parliamentary Research Service, Sydney.

Rawat P and Morris JC (2016) Kingdon's "Streams" Model at Thirty: Still Relevant in the 21st Century? Politics and Policy 44(4): 608-638.

Roberts ME, Stewart BM and Tingley D (2016) Stm: Estimation of the Structural Topic Model, https:// cran.r-project.org/web/packages/stm/index.html (accessed 28 August 2016).

Robinson SE and Eller WS (2010) Participation in Policy Streams: Testing the Separation of Problems and Solutions in Subnational Policy Systems. Policy Studies Journal 38(2): 199-216.

Sager F and Thomann E (2017) Multiple Streams in Member State Implementation: Politics, Problem Construction and Policy Paths in Swiss Asylum Policy. Journal of Public Policy 37(3): 287-314.

Schön DA and Rein M (1994) Frame Reflection: Toward the Resolution of Intractable Policy Controversies. New York: Basic Books.

Shanahan EA, McBeth MK and Hathaway PL (2011) Narrative Policy Framework: The Influence of Media Policy Narratives on Public Opinion. Politics \& Policy 39(3): 373-400.

Stedman RC, Jacquet JB, Filteau MR, Willits FK, Brasier KJ and McLaughlin DK (2012) Environmental Reviews and Case Studies: Marcellus Shale Gas Development and New Boomtown Research: Views of New York and Pennsylvania Residents. Environmental Practice 14(4): 382-393. 
Stone D (1998) Policy Paradox and Political Reason. Boston, MA: Little Brown.

Strömbäck J (2008) Four Phases of Mediatization: An Analysis of the Mediatization of Politics. The International Journal of Press/Politics 13(3): 228-246.

Tuchman G (1978) Television News and the Metaphor of Myth. Studies in the Anthropology of Visual Communications 5(1): 56-62.

Van Holt T, Johnson JC, Carley KM, Brinkley J and Diesner J (2013) Rapid Ethnographic Assessment for Cultural Mapping. Poetics 41(4): 366-383.

Van Hulst MJ and Yanow D (2016) From Policy "Frames" to "Framing". The American Review of Public Administration 26(1): 92-112.

Weible CM and Schlager E (2016) The Multiple Streams Approach at the Theoretical and Empirical Crossroads: An Introduction to a Special Issue. Policy Studies Journal 44(1): 5-12.

Winkel G and Leipold S (2016) Demolishing Dikes: Multiple Streams and Policy Discourse Analysis. Policy Studies Journal 44(1): 108-129.

Zahariadis N (2003) Ambiguity and Choice in Public Policy: Political Manipulation in Democratic Societies. Washington, DC: Georgetown University Press.

Zahariadis N (2007) The Multiple Streams Framework: Structure, Limitations, Prospects. In Sabatier PA (ed.), Theories of the Policy Process, 2nd ed. Boulder, CO: Westview Press, 65-92.

Zahariadis N (2016) Delphic Oracles: Ambiguity, Institutions, and Multiple Streams. Policy Sciences 49(1): 3-12.

Zohlnhöfer R, Herweg N and Rüb F (2015) Theoretically Refining the Multiple Streams Framework: An Introduction. European Journal of Political Research 54(3): 412-418.

Cite this article: Fawcett P., Jensen M., Ransan-Cooper H. and Duus S. 2019. Explaining the "ebb and flow" of the problem stream: frame conflicts over the future of coal seam gas ("fracking") in Australia. Journal of Public Policy 39: 521-541, doi:10.1017/S0143814X18000132 